\title{
Quantizing scalar change *
}

\author{
Robert Henderson \\ Wayne State University
}

\begin{abstract}
This paper provides a new analysis of N-BY-N adverbials that captures their previously unrecognized close connection to verbs of scalar change. After providing a series of arguments that N-B Y-N modification requires the VP to provide a scalar interval it can measure, we use this as novel evidence that incremental theme verbs, as well as inherently directed motion and change of state verbs, must make reference to scales. The analysis thus supports a unified scalar account of verbs of variable telicity (e.g., Hay, Kennedy \& Levin 1999; Kennedy \& Levin 2008; Kennedy 2012). Finally, we show that our analysis avoids empirical problems for previous approaches to these adverbials in both English (Beck \& von Stechow 2007; Brasoveanu \& Henderson 2009) and Russian (Braginsky \& Rothstein 2008).
\end{abstract}

Keywords: scalar change, pluractional adverbials

\section{Introduction}

Verbs of variable telicity have played a central role in the understanding of the semantics of aspect and aspectual composition. At the heart of this literature are the INCREMENTAL THEME (IT) verbs, whose telicity is intimately wrapped up with object reference, as (1) shows. Very broadly, a verb phrase headed by one of these predicates is telic just in case its internal argument makes reference to a bounded quantity.

(1) a. John ate a tuna sandwich in 10 minutes $/ *$ for ten minutes.

b. John ate tuna $*$ in 10 minutes / for ten minutes.

c. Mary built a house in three weeks / $*$ for three weeks.

d. Mary built houses $*$ in three weeks / for three weeks.

While incremental theme verbs are the prototypical verbs of variable telicity, the literature now recognizes at least two more subtypes: (i) the CHANGE OF STATE

* I need to thank Judith Aissen, Ryan Bennett, Adrian Brasoveanu, Jakub Dotlačil, Donka Farkas, and Beth Levin for productive discussions on earlier drafts of this work. I also need to thank four SALT reviewers and the participants of SALT 23 for their comments, which have greatly improved the current paper. Of course, any remaining errors are my own.

(C)2013 Henderson 
(COS) verbs in (2), and (ii) the INHERENTLY DIRECTED MOTION (IDM) verbs in (3).

(2) a. The crack widened for 30 seconds / $*$ in 30 seconds.

b. The crack widened 10 inches $*$ for 30 seconds / in 30 seconds

c. The stalactite lengthened for a million years / $*$ in a million years.

d. The stalactite lengthened to the floor $*$ for a million years / in a million years.

(3) a. John walked for an hour / *in an hour.

b. John walked to the store $*$ for an hour / in an hour.

c. The plane ascended for 5 minutes / $*$ in 5 minutes.

d. The plane ascended $1000 \mathrm{~m} *$ for 5 minutes / in 5 minutes.

COS and IDM verbs present a challenge for classic analyses of verbs of variable telicity because they do not entail that an argument's mereological constitution changes over the course of an event. For example, the seminal work of Krifka (1989, 1992) accounts for the contrasts in (1) by positing a special thematic role, gradual patient, which requires a homomorphism between the subprocesses of a verb's event argument and the subparts of its internal argument. It should be clear that this type of account does not immediately extend to examples like (2-3). For example, the verb ascend does not relate the parts of an ascending object with the parts of an ascending event. While a Krifka-type account can be extended to account for COS and IDM verbs (Ramchand 1997), a different strand of research aims not to extend an analysis of incremental theme verbs to the other two classes, but to subsume all three under a more general theory of scalar change (Hay et al. 1999; Kennedy \& Levin 2008; Kennedy 2012). The idea is that all three classes of verbs describe how an individual changes over the course of an event along some scalar dimension. For IT verbs, the dimension is the mereological constitution or extent of the object. For IDM verbs, it is an abstract path, and for COS verbs, it is the particular dimension encoded by the predicate itself.

The primary goal of this paper is to provide new evidence for a unified scalar account of IT, IDM, and COS verbs based on the behavior of N-BY-N adverbials like those in (4), which target verbs of all three classes.

(4) a. John ate the cake piece by piece.

b. Meter by meter, the plane slowly descended through the storm.

c. The carpenter shortened the beam inch by inch until it fit. 
In particular, I argue that if N-BY-N adverbials are to have similar denotations across the examples in (4), they must make reference to scales within a theory of verbs of scalar change that includes IT verbs as a subtype. The core proposal is that N-BY-N adverbials fix the unit of scalar change, i.e., they quantize the change, and then require a plural event to proceed in terms of those atomic changes. Crucially, this will not be possible unless each of the modified VPs in (4) are degree-denoting, exactly as previous authors have argued, in order to capture their variable telicity (Hay et al. 1999; Kennedy \& Levin 2008; Kennedy 2012).

This new analysis of N-BY-N adverbials not only captures their close connection to verbs of scalar change, but it is shown to have empirical advantages over the three previous proposals for N-BY-N in the literature. The first two, namely Beck \& von Stechow 2007 and Brasoveanu \& Henderson 2009, too closely tie N-BY-N to incremental changes in an argument's mereological constitution. That is, they create predicates with an analog of Krifka's gradual patient property, and so just as with Krifka's account, they cannot easily account for the interaction of N-BY-N adverbials with other verbs of scalar change, like $(4 b, 4 c)$. The third type of account, developed first in Braginsky \& Rothstein 2008 for the analogous N-ZA-N adverbials in Russian, does not recognize the systematic connection between these adverbials and VPs that denote scalar changes. In particular, even though $\mathrm{N}-\mathrm{ZA}-\mathrm{N}$ denotes a measure function in Braginsky \& Rothstein 2008, the licensing of N-ZA-N is instead dependent on the aktionsart of the modified VP, which we show to be incorrect for English.

\section{N-BY-N modifies VPs that denote scalar changes}

First, consider the fact that N-BY-N can modify verbs that clearly denote scalar changes. Moreover, when they do, they contain measure nouns, which are commonly taken to denote predicates of scalar intervals (Schwarzschild 2006; Zwarts 1997). If we assume a fairly transparent semantics for the N-BY-N construction as as whole, then the VP it modifies must provide a scalar interval for the measure noun to be predicated of.

(5) Change of state verbs

a. The crack widened inch by inch.

b. I warmed the patient degree by degree until he was no longer in danger.

c. The turkey was fattened pound by pound.

d. The designer lightened the background shade by shade until she was pleased with the composition.

(6) Inherently directed motion verbs 
a. The plane descended meter by meter until it reached a safe altitude.

b. Step by step John ascended the mountain.

c. They lowered the basket inch by inch.

d. The interest rate was slowly raised percentage point by percentage point.

While the data in (5-6) show that N-BY-N adverbials can set the increment for a verb of scalar change, they do not show that they must. To do so, we must show that N-BY-N modification is dependent on verbs of scalar change. There are four arguments that this is the case, all of which are new to the literature.

First, if N-BY-N adverbials necessarily elaborate on scalar changes, then they should be uniformly ungrammatical with verbs of non-scalar change. As Levin \& Rappaport Hovav 2010 discusses, verbs of non-scalar change come in two types and describe changes that cannot be characterized as an ordered set of degrees. The first type lack an ordering relation. The second are, in some sense, too complex to isolate a scale of change. Both types of verbs resist modification by N-BY-N adverbials. In fact, it is hard for speakers to even think of potential N-BY-N adverbials to modify such predicates.

(7) Verbs of change without an order

a. The ball floated $*$ foot by foot $/ *$ gust by gust/*throw by throw/*day by day.

b. The top spun $*$ inch by inch/*circle by circle/*twist by twist.

c. The dancer whirled $*$ step by step/*song by song/*minute by minute.

(8) Verbs of complex changes

a. John exercised $*$ step by step/*machine by machine/*drill by drill.

b. Susan waved $*$ hand by hand $/ *$ foot by foot.

c. George shuddered $*$ chill by chill/*extremity by extremity/*flurry by flurry. It is not even possible to target the subparts of an individual when N-BY-N modifies these predicates, unlike with IT verbs.

a. * The ballerinas whirled dancer by dancer.

b. * The graduating seniors waved student by student.

c. * The platoon exercised soldier by soldier.

Another argument that N-BY-N modification makes reference to scales comes from the effect of resultatives on their grammaticality. It is well known that nonscalar change verbs, many of which lexicalize a manner, start to behave like verbs of scalar change when modified by a resultative (Levin \& Rappaport Hovav 2010). The prediction is that N-BY-N modifiers should be grammatical only in the latter case. This is borne out. 
Quantizing scalar change

(10) a. * Crumb by crumb, Bill licked the plate.

b. Crumb by crumb, Bill licked the plate clean.

(11) a. Erica wiped the table $*$ smudge by smudge.

b. Erica wiped the table clean smudge by smudge.

(12) a. Lily pried the door *inch by inch.

b. Lily pried the door open inch by inch.

If resultatives transform pure manner verbs into verbs of scalar change, then the contrast between the (a) examples and the (b) examples in (10-12) can be attributed to the sensitivity of N-B Y-N modification to scalar change. ${ }^{1}$

The next argument, which has a similar form to the previous one, comes from verbs like climb. As Levin \& Rappaport Hovav 2010 shows, these verbs are ambiguous between a scalar, IDM interpretation and a manner interpretation. Example (13) illustrates that the direct object can disambiguate the relevant readings. Climbing a ladder clearly involves directed motion, while climbing the monkey bars does not. If N-BY-N can only modify VPs that denote scalar changes, then climb should be ungrammatical with $\mathrm{N}-\mathrm{BY}-\mathrm{N}$ when the object favors the manner reading. This prediction is borne out in example (14).

(13) a. John climbed the ladder.

b. John climbed the monkey bars.

(14) a. John climbed the ladder rung by rung.

b. John climbed the monkey bars *rung by rung/*bar by bar.

Once again, the data show that the availability of N-BY-N modification is correlated with VPs that denote scalar changes.

The final argument comes from the fact that IT verbs do not lexicalize a scale, but inherit it from the extent of their objects (Kennedy 2012; Levin \& Rappaport Hovav 2010). Thus, IT verbs that allow implicit arguments should resist modification by $\mathrm{N}$-BY-N when they do not happen to have a direct object. Examples (15-16) show that this prediction is correct.

1 Given that resultatives also derive telic VPs, one might worry that this test is confounded and that telicity is what is at issue. Note though that $N$-by- $N$ modification is perfectly acceptable with an atelic VP when it is headed by scalar change verb. This issue is taken up in more detail in section 4.

The crack widened inch by inch for three hours. 
(15) a. John ate the pie slice by slice.

b. John ate $*$ slice by slice.

(16) a. Mary drank the whiskey shot by shot.

b. Mary drank $*$ shot by shot.

Not only do these data support the proposal that N-BY-N modification tracks VPs that denote scalar changes, they also verify an important difference between IT verbs on one hand and IDM and COS verbs on the other. The latter verbs lexicalize a scale that N-BY-N can use, while IT verbs do not. This fact will have consequences for developing a unified account of N-BY-N.

\section{An analysis in increments}

The account proceeds by first accounting for the behavior of N-BY-N adverbials with canonical verbs of scalar change like COS and IDM verbs. I then extend the analysis to IT verbs, which have been shown to be different in that they do not lexicalize a scale. Instead, the physical extent of the theme argument is used as a scale.

I assume the account of scalar change verbs in Kennedy \& Levin 2008, which builds on work in Hay et al. 1999. The idea is that verbs of scalar change denote measure-of-change functions. They map individuals and events to a degree on a scale that is the difference between the degree associated with that individual at the end of the event and the degree associated with that individual at the start of the event. $^{2}$ A sentence like (17) will have the interpretation in (18). ${ }^{3}$

$\mathrm{It}_{x}$ widened.

$$
\exists e\left[\operatorname{WIDE}_{\Delta}^{\mathbf{a g}}(e) \geq \mathbf{s t n d}\left(\operatorname{WIDE}_{\Delta}\right) \wedge \mathbf{a g}(e)=x\right]
$$

'There is an event $e$, and the degree that $x$ widens over the course of $e$ is larger than the standard for widening.'

The formulas in (19-20) unpack the $\Delta$-notation, making the denotation in (18) clearer.

(19) Difference Function (Kennedy \& Levin 2008: ex. 23)

For any measure function $\mathbf{m}$ from objects and times to degrees on a scale $S$, and for any $d \in S, \mathbf{m}_{d}^{\uparrow}$ is a function just like $\mathbf{m}$ except that:

2 A scale $S$ is a triple $\langle D, R, \delta\rangle$ where: $D$ is a set of degrees, $R$ is an ordering on $D, \delta$ is the dimension of measurement.

3 I have altered the account in Kennedy \& Levin 2008 by allowing verbal measure functions, which are the only kind we consider here, to access their individual arguments through theta-role functions. 
Quantizing scalar change

a. its range is $\left\{d^{\prime} \in S \mid d \leq d^{\prime}\right\}$, and

b. for any $x, t$ in the domain of $\mathbf{m}$, if $\mathbf{m}(x)(t) \leq d$ then $\mathbf{m}_{d}^{\uparrow}(x)(t)=d$.

' $m_{d}^{\uparrow}$ measures objects relative to a specified degree $d$.'

(20) Measure of Change (Kennedy \& Levin 2008: ex. 25)

For any measure function $\mathbf{m}, \mathbf{m}_{\Delta}^{\theta}::=\lambda e\left[\mathbf{m}_{\mathbf{m}(\theta(e))(\operatorname{init}(e))}^{\uparrow}(\theta(e))(\operatorname{fin}(e))\right]$

'Returns a degree representing the difference in the degree $\theta(e)$ has on the scale associated with $\mathbf{m}$ at the start and end of $e$.'

Against this backdrop, I propose that N-BY-N adverbials are eventive modifiers that elaborate on a measure-of-change function supplied by the VP. In particular, they require the macro-event to be a plurality of atomic events that are linearly ordered in time. Moreover, they then take the scalar interval that each of these atomic events is mapped to by the VP's measure function and say that this interval is the unit relative to the adverbial's measure noun. ${ }^{4}$ The result is that the adverbial sets the unit for a plurality of scalar changes. To see an example in detail, consider (22), which gives the interpretation of example (21), using the abbreviation in (23). ${ }^{5}$

(21) It $_{x}$ widened inch by inch.

$$
\begin{aligned}
& \exists e\left[\operatorname{WIDE}_{\Delta}^{\mathbf{a g}}(e) \geq \mathbf{s t n d}\left(\mathrm{WIDE}_{\Delta}\right) \wedge \mathbf{a g}(e)=x \wedge\right. \\
& |\operatorname{atoms}(e)|>1 \wedge \\
& \text { linear.order }(\operatorname{atoms}(e)) \wedge \\
& \forall e^{\prime} \sqsubseteq e\left[\operatorname{atom}\left(e^{\prime}\right) \rightarrow \operatorname{INCH}\left(\mathrm{WIDE}_{\Delta}^{\mathbf{a g}}\left(e^{\prime}\right)\right)=1\right] \wedge \\
& \left.\forall e^{\prime} \sqsubset e\left[\operatorname{INCH}\left(\operatorname{WIDE}_{\Delta}^{\mathbf{a g}}\left(e^{\prime}\right)\right)<\operatorname{INCH}\left(\mathrm{WIDE}_{\Delta}^{\mathbf{a g}}(e)\right)\right]\right] \\
& \operatorname{atoms}(e)::=\left\{e^{\prime} \sqsubseteq e: \operatorname{atom}\left(e^{\prime}\right)\right\}
\end{aligned}
$$

The first line is exactly like that in (18). Although inch by inch contributes quite a few conditions, it is still a widening event. The next two lines require $e$ to be a widening event with a plurality of atomic parts that are linearly ordered in time. The fourth line shows why N-BY-N must modify a VP that makes reference to scales. It takes the measure function the verb denotes and requires that each atomic event in $e$ is mapped to an interval that is one inch long, that is, each atomic widening event is an event of widening one inch. Finally, the last line says that the individual argument becomes more wide over the course of the whole event than over any of its subevents. This last line is necessary to successfully rule out the truth of (21) in scenarios like (24).

4 I follow Lønning 1987 in assuming that degrees are not numbers, but that expressions like inch, meter, pound, etc. map degrees to numbers.

5 Note that I use $\sqsubseteq$ for mereological parthood, but $\leq$ to order both degrees and cardinalities. 
(24) Suppose a crack widens one inch, then closes again, then widens one inch again, then closes again, etc.

a. \# The crack widened inch by inch.

The analysis in (22) thus captures the bottom-line truth conditions of (21). It will be true if there is a widening event with many parts, each of which is an event of widening one inch. Moreover, none of these events take place at the same time, and the individual widens at least two inches over the course of the big event. Most importantly, the analysis captures the generalization that was argued for extensively in the previous section. The VP must provide a measure function that maps events to a degrees that N-BY-N can measure. The problem with examples like (25), as shown in (26), is that exercise is a predicate of events. Even though we can understand what (25) would mean, exercise just does not map events to entities in the domain of the measure noun inch. An $\boldsymbol{X}$ marks those places in (26) where composition fails.

* John exercised meter by meter.

$$
\begin{aligned}
& \exists e[\operatorname{EXERCISE}(e) \wedge \mathbf{a g}(e)=x \wedge \\
& |\operatorname{atoms}(e)|>1 \wedge \\
& \operatorname{linear} . \mathbf{o r d e r}(\operatorname{atoms}(e)) \wedge \\
& \forall e^{\prime} \sqsubseteq e\left[\operatorname{atom}\left(e^{\prime}\right) \rightarrow \operatorname{INCH}\left(\boldsymbol{X} \operatorname{EXERCISE}\left(e^{\prime}\right)\right)=1\right] \wedge \\
& \left.\forall e^{\prime} \sqsubset e\left[\operatorname{INCH}\left(\boldsymbol{X} \operatorname{EXERCISE}\left(e^{\prime}\right)\right)<\operatorname{INCH}(\boldsymbol{X} \operatorname{EXERCISE}(e))\right]\right]
\end{aligned}
$$

A nice consequence is that we now have a unified explanation for why (27) and (25) are equally ungrammatical. Even through verbs like widen and ascend are measure functions, they do not map events to entities in the domain of the measure nouns pound and ounce, respectively.

$$
\begin{aligned}
& \text { a. * It widened pound by pound. } \\
& \text { b. * John ascended ounce by ounce. }
\end{aligned}
$$

Example (25) is just another case in which N-B Y-N cannot access the right kinds of entities to measure.

While (21) contains a COS verb, the analysis immediately extends to IDM verbs if they are taken to denote measure functions. That is, if a verb like ascend in (28) is treated as a function from events and individuals to the distance that the individual changes in elevation over the course of the event. This is exactly what the interpretation in (29) shows.

$\mathrm{He}_{x}$ ascended meter by meter. 
Quantizing scalar change

$$
\begin{aligned}
& \exists e\left[\operatorname{ASCEND}{ }_{\Delta}^{\mathbf{a g}}(e) \geq \mathbf{s t n d}\left(\operatorname{ASCEND}_{\Delta}\right) \wedge \mathbf{a g}(e)=x \wedge\right. \\
& |\mathbf{a t o m s}(e)|>1 \wedge \\
& \text { linear.order }(\operatorname{atoms}(e)) \wedge \\
& \forall e^{\prime} \sqsubseteq e\left[\operatorname{atom}\left(e^{\prime}\right) \rightarrow \operatorname{METER}^{\prime}\left(\operatorname{ASCEND}_{\Delta}^{\mathbf{a g}}\left(e^{\prime}\right)\right)=1\right] \wedge \\
& \left.\forall e^{\prime} \sqsubset e\left[\operatorname{METER}\left(\operatorname{ASCEND}_{\Delta}^{\mathbf{a g}}\left(e^{\prime}\right)\right)<\operatorname{METER}^{\mathbf{a g}}\left(\operatorname{ASCEND}_{\Delta}^{\mathbf{a g}}(e)\right)\right]\right]
\end{aligned}
$$

In a manner parallel to (21), example (28) will be true if there is an ascending event that $x$ is the agent of. Moreover, that event must be decomposable into a plurality of linearly ordered atomic ascending events, each of which is an event of $x$ ascending one meter. Finally, $x$ must ascend at least two meters over the course of the big event.

Though the analysis successfully captures the truth conditions of N-BY-N with IDM and COS verbs in a unified way, it is not so surprising. Both IDM and COS verbs lexicalize a measure function in precisely the same way (Kennedy 2012; Levin \& Rappaport Hovav 2010). More difficult are the IT verbs, like drink and eat in (30-31), which do not lexicalize a measure function.

She ${ }_{x}$ drank the whiskey shot by shot.

$$
\mathrm{She}_{x} \text { ate the pizza slice by slice. }
$$

At first pass, it might look like there is no real measurement going on in these examples, but we can show that there is. While a shot can refer to a particular kind of glass holding 1.5 fluid ounces of liquid, it can also refer to the amount of liquid alone. To see this, note that we could use (30) truthfully in a situation in which the subject drank the whiskey from a bottle that had one of those special caps that only let out 1.5 ounces at a time. This clearly shows that (30) involves an abstract measure, just like those examples with inch by inch or pound by pound. One might be more skeptical that slice in (31) can be used as a measure of physical extent, but there is evidence that it can be. Suppose you ask for a slice of pizza and someone brings you this huge slice. It is perfectly acceptable to say something like (32).

(32) That's not a slice, that's 3 slices.

These considerations show that (30-31) plausibly involve real measurement, but what provides the degrees that they measure? In examples like (28-29), ascend is a function from events and individuals to the degree in elevation the individual changes over the course of the event. The adverbial meter by meter can then measure those degrees in terms of meters. To have a unified account of N-BY-N, we must say that IT verbs can be converted into measures of an argument's physical extent, e.g., DRINK : $\langle\varepsilon, t\rangle$ becomes DRINK ${ }_{\Delta}^{\text {th }}:\langle\varepsilon, d\rangle$, a function from events to degrees representing the volume of the theme consumed over the course of the event. ${ }^{6}$ With

6 That is, we could think that the alternation between DRINK and DRINK th $_{\Delta}$ in (33) is due to a type of coercion that is available to IT verbs, but not verbs like exercise in (26). 
this assumption in place, example (30) can be translated like (33).

$$
\begin{aligned}
& \exists e[\operatorname{DRINK}(e) \wedge \operatorname{ag}(e)=x \wedge \operatorname{th}(e)=\sigma x . * \operatorname{WHISKEY}(y) \wedge \\
& |\operatorname{atoms}(e)|>1 \wedge \\
& \operatorname{linear.order}(\operatorname{atoms}(e)) \wedge \\
& \forall e^{\prime} \sqsubseteq e\left[\operatorname{atom}\left(e^{\prime}\right) \rightarrow \operatorname{SHOT}\left(\operatorname{DRINK}_{\Delta}^{\mathbf{t h}}\left(e^{\prime}\right)\right)=1\right] \wedge \\
& \left.\forall e^{\prime} \sqsubset e\left[\operatorname{SHOT}^{\prime}\left(\operatorname{DRINK}_{\Delta}^{\mathbf{t h}}\left(e^{\prime}\right)\right)<\operatorname{SHOT}^{\prime}\left(\operatorname{DRINK}_{\Delta}^{\mathbf{t h}}(e)\right)\right]\right]
\end{aligned}
$$

Example (33) is true just in case there is a drinking event whose agent is $x$ and whose theme is the whiskey. Moreover, this event must be able to be broken into a plurality of linearly ordered atomic parts, each of which has a theme whose volume is a shot. Finally, the volume of what is drunk over the course of the whole event is more than what is drunk in any of its parts. While (33) does generate the intuitively correct interpretation of (31), it makes at least one more correct prediction. Because the derived IT measure-of-change function DRINK ${ }_{\Delta}^{\text {th }}$ is dependent on a theme argument, we correctly predict that objectless IT verbs, like those in (15-16), should be ungrammatical with N-BY-N.

With this analysis of IT verbs under N-BY-N modification, we have successfully provided a unified account of N-BY-N in which it elaborates on events of scalar change. Most importantly, this explains the data in section 2, which show that the availability of N-BY-N modification closely tracks diagnostics in the previously literature for VPs that denote scalar changes. The interim conclusion is that N-BY-N modification provides more evidence that IT, COS, and IDM verbs pattern together, just as previous authors have argued (Hay et al. 1999; Kennedy \& Levin 2008; Kennedy 2012). Moreover, we have shown that we can capture the unified behavior of these three verb classes with respect to N-BY-N if these verbs denote scalar changes and if $\mathrm{N}-\mathrm{BY}-\mathrm{N}$ is a scalar modifier.

\section{Comparing previous approaches}

The previous two sections have argued at length for an analysis of $\mathrm{N}-\mathrm{BY}-\mathrm{N}$ that makes it dependent on scalar change. This section shows that the data presented in section 2, and captured straightforwardly in section 3, cause problems for the three previous analysis of $\mathrm{N}-\mathrm{B}$ Y-N adverbials.

\subsection{Part-Whole approaches}

Let's first consider the analyses in Brasoveanu \& Henderson 2009 and Beck \& von Stechow 2007, which are cast in terms of changes in the mereological constitution 
Quantizing scalar change

of an individual argument over the course of the event. We find that they cannot account for the fact that N-BY-N freely modifies COS and IDM verbs.

Brasoveanu \& Henderson 2009 are primarily focused on NUM-B Y-NUM adverbials like one by one, but their analysis is clearly meant to be extended to N-BY-N with only minimal modifications. While we will ignore their treatment of the syntaxsemantics interface, which makes extensive use of theta-role indexing in the syntax to guide composition, they give one by one a translation like (34) below.

$$
\begin{aligned}
& \text { one by one }_{\theta} \rightsquigarrow \lambda E_{\varepsilon t} \cdot \lambda e_{\varepsilon} \cdot E(e) \wedge \\
& \text { linear.order }\left(\left\{e^{\prime} \leq e: \operatorname{atom}\left(e^{\prime}\right)\right\}\right) \wedge \\
& \left|\left\{\theta\left(e^{\prime}\right): e^{\prime} \leq e \wedge \operatorname{atom}\left(e^{\prime}\right)\right\}\right|>1 \wedge \\
& \forall e^{\prime} \leq e\left(\operatorname{atom}\left(e^{\prime}\right) \rightarrow \operatorname{atom}\left(\theta\left(e^{\prime}\right)\right)\right)
\end{aligned}
$$

We can see here that a NUM-BY-NUM adverbial requires the event argument to be a plural event and the indexing theta-role must map that event to a plural individual. The event's parts must be temporally sequenced and each atomic part must be mapped by the indexing theta-role to an individual of the cardinality given by NUM, in this case, one or equivalently, by the predicate atom. The interpretation for a sentence like (35) is provided in (36) below. A picture of the resulting interpretation is shown in (37).

$$
\begin{aligned}
& \text { The }^{\text {ag }} \text { boys recited “The Raven"th one by one } \\
& \text { ag. } \\
& \exists e_{\varepsilon}(\operatorname{RECITE}(e) \wedge \operatorname{th}(e)=\operatorname{THE}-\operatorname{RAVEN} \wedge \\
& \operatorname{ag}(e)=\sigma x .^{*} \operatorname{BOY}(x) \wedge \operatorname{runtime}(e) \prec \mathbf{t}_{\text {now }} \wedge \\
& \operatorname{linear} \cdot \operatorname{order}\left(\left\{e^{\prime} \leq e: \operatorname{atom}\left(e^{\prime}\right)\right\}\right) \wedge \\
& \left|\left\{\operatorname{ag}\left(e^{\prime}\right): e^{\prime} \leq e \wedge \operatorname{atom}\left(e^{\prime}\right)\right\}\right|>1 \wedge \\
& \left.\forall e^{\prime} \leq e\left(\operatorname{atom}\left(e^{\prime}\right) \rightarrow \operatorname{atom}\left(\operatorname{ag}\left(e^{\prime}\right)\right)\right)\right)
\end{aligned}
$$

$$
\begin{aligned}
& e= \\
& \begin{array}{c}
e_{1} \\
\operatorname{atom}\left(e_{1}\right)
\end{array} \\
& \oplus \quad e_{2} \\
& \operatorname{runtime}\left(e_{1}\right) \prec \operatorname{runtime}\left(e_{2}\right) \prec \ldots
\end{aligned}
$$

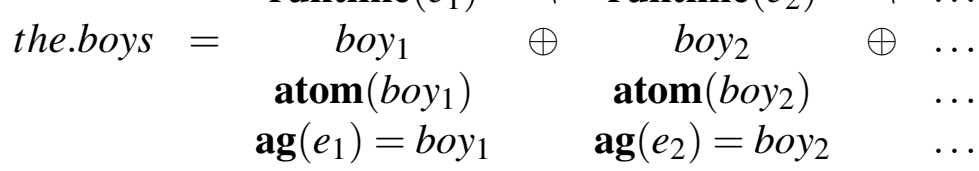

The formula in (36) is true just in case there is an event $e$ of reciting "The Raven," which has at least two atomic parts that are linearly ordered by time, and which are mapped by ag to two different parts of the sum of some contextually salient boys.

As mentioned, while Brasoveanu \& Henderson (2009) discuss N-BY-N adverbials, they do not provide an analysis of them. A minimal extension of their account, though, would treat them like in (38). 


$$
\begin{aligned}
& N \text { by } N_{\theta} \rightsquigarrow \lambda E_{\varepsilon t} \cdot \lambda e_{\varepsilon} \cdot E(e) \wedge \\
& \text { linear.order }\left(\left\{e^{\prime} \leq e: \operatorname{atom}\left(e^{\prime}\right)\right\}\right) \wedge \\
& \left|\left\{\theta\left(e^{\prime}\right): e^{\prime} \leq e \wedge \operatorname{atom}\left(e^{\prime}\right)\right\}\right|>1 \wedge \\
& \forall e^{\prime} \leq e\left(\operatorname{atom}\left(e^{\prime}\right) \rightarrow \widetilde{N}\left(\theta\left(e^{\prime}\right)\right)\right)
\end{aligned}
$$

The resulting translation for sentence (39) is provided in (40) below. The plural event $e$ of eating is broken into atomic subevents $e^{\prime}$ that satisfy three properties: $(i)$ the subevents are temporally sequenced, (ii) they involve more than one entity as their theme, and (iii) each and every one of their themes is a piece. That each such piece is actually a piece of cake follows from the fact that the macro-event $e$ has the cake as its theme.

(39) John ate the ${ }^{\text {th }}$ cake piece by piece th $_{\text {. }}$

$$
\begin{aligned}
& \exists e_{\varepsilon}\left(\operatorname{EAT}(e) \wedge \operatorname{th}(e)=\sigma x \cdot \mathrm{CAKE}(x) \wedge \operatorname{ag}(e)=\operatorname{JOHN} \wedge \operatorname{runtime}(e) \prec \mathbf{t}_{\text {now }} \wedge\right. \\
& \operatorname{linear.order}\left(\left\{e^{\prime} \leq e: \operatorname{atom}\left(e^{\prime}\right)\right\}\right) \wedge \\
& \left|\left\{\operatorname{th}\left(e^{\prime}\right): e^{\prime} \leq e \wedge \operatorname{atom}\left(e^{\prime}\right)\right\}\right|>1 \wedge \\
& \left.\forall e^{\prime} \leq e\left(\operatorname{atom}\left(e^{\prime}\right) \rightarrow \operatorname{PIECE}\left(\operatorname{th}\left(e^{\prime}\right)\right)\right)\right)
\end{aligned}
$$

While the analysis clearly captures the intuitively correct interpretation of (39), notice that eat is an IT verb. As such, the physical extent of its internal argument provides a way to measure out the event. This means that structuring how parts of the individual argument participate in parts of the event argument, as Brasoveanu \& Henderson (2009) do, is the same as measuring events in terms of the physical extent of an argument, as we do in section 3. The analyses come apart, though, when we consider the interaction of N-BY-N with IDM and COS verbs. Consider example (41), which contains an IDM verb. Its interpretation, following Brasoveanu \& Henderson 2009, would be (42).

(41) The ${ }^{\mathbf{a g}}$ plane descended meter by meter $\mathbf{a g}$.

$$
\begin{aligned}
& \exists e_{\varepsilon}\left(\operatorname{DESCEND}(e) \wedge \operatorname{ag}(e)=\sigma x . \operatorname{PLANE}(x) \wedge \operatorname{runtime}(e) \prec \mathbf{t}_{\text {now }} \wedge\right. \\
& \operatorname{linear} . \operatorname{order}\left(\left\{e^{\prime} \leq e: \operatorname{atom}\left(e^{\prime}\right)\right\}\right) \wedge \\
& \left|\left\{\operatorname{th}\left(e^{\prime}\right): e^{\prime} \leq e \wedge \operatorname{atom}\left(e^{\prime}\right)\right\}\right|>1 \wedge \\
& \left.\forall e^{\prime} \leq e\left(\operatorname{atom}\left(e^{\prime}\right) \rightarrow \operatorname{METER}\left(\operatorname{th}\left(e^{\prime}\right)\right)\right)\right)
\end{aligned}
$$

Even under a charitable interpretation, (42) is nonsense. It would be true if there were a sequence of descending events, and each of those events had a meter-long part of the plane as its agent. The problem is that (41) does not describe how parts of an argument participate in a plural event over time. Instead, it describes how the argument as a whole changes relative to a measure. The analysis developed in section 3 is able to account for (41) straightforwardly because it is couched in terms 
of scalar changes. In contrast, the account in Brasoveanu \& Henderson 2009, which is couched in terms of parts and wholes, cannot be easily extended to deal with the modification of IDM and COS verbs by N-BY-N.

The analysis in Brasoveanu \& Henderson 2009 not only undergenerates, it also overgenerates. Since the analysis does not treat N-BY-N as a scalar modifier, it incorrectly predicts that it should be grammatical with predicates of non-scalar change. For example, Brasoveanu \& Henderson 2009 would give (43) the translation in (44), which is perfectly coherent. It is true if the ballerinas are the agent of a whirling event whose atomic parts are linearly ordered in time and have dancers as agents.

* The ballerinas whirled dancer by dancer.

$$
\exists e_{\varepsilon}\left(\operatorname{WHIRL}(e) \wedge \mathbf{a g}(e)=\sigma x . * \operatorname{BALLERINAS}(x) \wedge \operatorname{runtime}(e) \prec \mathbf{t}_{\text {now }} \wedge\right.
$$

linear.order $\left(\left\{e^{\prime} \leq e: \operatorname{atom}\left(e^{\prime}\right)\right\}\right) \wedge$

$\left|\left\{\operatorname{ag}\left(e^{\prime}\right): e^{\prime} \leq e \wedge \operatorname{atom}\left(e^{\prime}\right)\right\}\right|>1 \wedge$

$\left.\forall e^{\prime} \leq e\left(\operatorname{atom}\left(e^{\prime}\right) \rightarrow \operatorname{DANCER}\left(\operatorname{ag}\left(e^{\prime}\right)\right)\right)\right)$

It is not hard to imagine a simple situation in which (44) is true, for example, at a performance where each dancer enters the stage whirling. The problem is that (43) cannot mean this. Brasoveanu \& Henderson 2009 cannot predict the infelicity of (44), though a scalar treatment does so immediately.

We have seen that the analysis in Brasoveanu \& Henderson 2009 both undergenerates and overgenerates because it fails to recognize the tight connection between N-BY-N and verbs of scalar change. While the analysis in Beck \& von Stechow 2007 has a radically difference syntax-semantics interface, it has the same set of problems. First, Beck \& von Stechow (2007) treat the N-BY-N construction as basic and use its analysis as the basis for the account of a variety of pluractional adverbials. Unlike Brasoveanu \& Henderson (2009), they are not primarily interested in distributivity, but in how verb phrases come to denote predicates of pluralities, especially under modification by N-BY-N adverbials. Thus, Beck \& von Stechow (2007) aim to compositionally generate the bottom-line truth conditions of sentences like (39), which they give as (45).

(39) is true of an event $e$ iff the relevant division of the cake is into pieces, and each piece was eaten by John in a relevant subevent of $e$, and each relevant subevent of $e$ is an eating of one of the pieces by John.

To generate the truth conditions in (45), Beck \& von Stechow (2007) take the term "pluractionality" at face value and introduce syntactically-covert pluralization operators, defined basically as in (46) below (see Beck \& von Stechow 2007: 234, 
ex. 66). ${ }^{7}$

$$
\begin{aligned}
& P L \rightsquigarrow \lambda \operatorname{Cov} \cdot \lambda R_{e(\varepsilon t)} \cdot \lambda x_{e} \cdot \lambda e_{\varepsilon} . \\
& \operatorname{PARTITION}(\operatorname{Cov}, e \oplus x) \wedge\left[* * \lambda y_{e} . \lambda e_{\varepsilon}^{\prime} \cdot \operatorname{Cov}\left(e^{\prime}\right) \wedge \operatorname{Cov}(y) \wedge R(y)\left(e^{\prime}\right)\right](x)(e)
\end{aligned}
$$

The operator $P L$ applies to a cover, a relation $R$ between individuals and events of type $e(\varepsilon t)$, a plural individual $x$, and a plural event $e$ and requires: $(i)$ the cover to be a partition of (the sum of) the plural event and the plural individual and (ii) each pair of subparts in the cover to satisfy the relation $R$. The operator $* *$ is cumulative closure over relations: for any $R$ of type $e(\varepsilon t),{ }^{*} R$ is the smallest relation such that $R \subseteq * * R$ and, if $\langle x, e\rangle,\left\langle y, e^{\prime}\right\rangle \in * * R$, then $\left\langle x \oplus y, e \oplus e^{\prime}\right\rangle \in * * R$.

The contribution of pluractional adverbials is to further constrain the cover over individuals $\operatorname{Cov}$ that the pluralization operator $P L$ requires. For example, the adverbial piece by piece requires each $y$ that is a part of $x$ (according to Cov) to be a piece (see (67c) and (70) in Beck \& von Stechow 2007: 234-235). The example in (47) below is assigned the logical form (LF) in (48) and is compositionally interpreted as shown in (49) (see Beck \& von Stechow 2007: 234, ex. 67). To derive the intuitively-correct interpretation, the direct object the cake has to be QR-ed and, crucially, we need to assume that the $\lambda$-abstractor associated with the QR-ed direct object is syntactically independent from it. This is needed because the pluralization operator $P L_{C o v}$ and the adverbial piece by piece have to be tucked between the QR-ed object and its associated $\lambda$-abstractor.

John ate the cake piece by piece.

$[\text { the cake }]_{2}\left[P L_{\text {Cov }}\left[\right.\right.$ piece by piece $\left[\lambda 2\left[\right.\right.$ John ate $\left.\left.\left.\left.t_{2}\right]\right]\right]\right]$

$$
\begin{aligned}
& \exists e\left(\text { runtime }(e) \prec \mathbf{t}_{\text {now }} \wedge \operatorname{PARTITION}(\operatorname{Cov}, e \oplus \operatorname{THE}-\mathrm{CAKE}) \wedge\right. \\
& \left.\langle e, \operatorname{THE}-\operatorname{CAKE}\rangle \in * * \lambda y \cdot \lambda e^{\prime} \cdot \operatorname{Cov}(y) \wedge \operatorname{Cov}\left(e^{\prime}\right) \wedge \operatorname{PIECE}(y) \wedge \operatorname{EAT}\left(e^{\prime}, \operatorname{JOHN}, y\right)\right)
\end{aligned}
$$

Example (49) gives exactly those intuitively correct truth conditions in (45). The sentence is true just in case you can divide the eating event and the cake into event-piece pairs, each of which satisfies the eating relation with John as its agent.

Just as with Brasoveanu \& Henderson 2009, the account in Beck \& von Stechow 2007 does not predict the ability of N-BY-N to modify COS and IDM verbs. The problem is that the analysis requires parts of the individual argument to satisfy the nominal in the N-BY-N adverbial. As we have seen, though, this type of relationship does not hold when N-BY-N modifies COS and IDM verbs. At the same time, the

7 In fact, the paper is built as an argument for the pervasiveness of cover-based, two place pluralization operators like (46) in natural language. 
Quantizing scalar change

analysis also overgenerates, predicting that N-BY-N can modify predicates of nonscalar change. Consider example (9a), which we have seen before. Beck \& von Stechow 2007 would give (9a) the interpretation in (50). We merely partition the main event and the ballerinas into parts where the event part is a whirling event and the individual part is a dancer. While the translation in (50) is perfectly coherent, example (9a) just does not have this reading.

$$
\begin{aligned}
& \exists e \exists \mathbf{d}\left(\text { runtime }(e) \prec \mathbf{t}_{\text {now }} \wedge P A R T \operatorname{ITION}(\operatorname{Cov}, e \oplus \operatorname{BALLERINA}) \wedge\right. \\
& \left.\langle e, \mathbf{x}\rangle \in * * \lambda \mathbf{y} \cdot \lambda e^{\prime} . \operatorname{Cov}(\mathbf{y}) \wedge \operatorname{Cov}\left(e^{\prime}\right) \wedge \operatorname{DANCER}(\mathbf{y}) \wedge \operatorname{WHIRL}\left(e^{\prime}, \mathbf{y}\right)\right)
\end{aligned}
$$

These two incorrect predictions show that Beck \& von Stechow 2007, like Brasoveanu \& Henderson 2009, misses an important generalization. N-B Y-N modification elaborates on scalar changes. By tying the analysis too closely to the part-whole structure of a nominal argument, both of these previous analyses fail to explain the distributional patterns introduced in section 2 . This puts the analysis developed in section 3 at a significant empirical advantage.

\subsection{A previous measure-based analysis}

While the two previous analyses of N-BY-N in English are similar, there are accounts of analogous adverbials in other languages that are closer to the analysis proposed in section 3. In particular, Braginsky \& Rothstein (2008) analyze Russian N-ZA$\mathrm{N}$ as a measure modifier that elaborates on the incremental chain of events that accomplishments denote. While this analysis can account for the fact that N-BY-N adverbials target verbs of scalar change, we show that it incorrectly restricts the distribution of these modifiers. While many verbs of scalar change are incidentally accomplishments, N-B Y-N does not care about the aktionsart of the verb phrase it modifies.

Russian N-ZA-N adverbials make only a small showing in Braginsky \& Rothstein 2008. The primary focus of the paper is the Russian counterpart of gradually, namely postepenno, which preferentially targets accomplishments. The idea underlying the analysis of $\mathrm{N}-\mathrm{ZA}-\mathrm{N}$ is that it is akin to postepenno, but it specifies, via a measure, how the gradual change proceeds.

Because this analysis is rooted in the analysis of accomplishments, let's first consider the treatment of accomplishments. While there is not enough space for a full exposition, the core idea is that accomplishments are composed of two events, an activity and a temporally extended BECOME event. The first conjunct in (51) says that the event $e$ is the sum of two temporally coextensive events. The rest of the first line in (51) requires $e_{1}$ to be an activity with a theme $x$. The second line says that $e_{2}$ is a BECOME event that shares an argument with the activity. Finally, (51) 
requires that $e_{1}, e_{2}$, and $C\left(e_{2}\right)$ stand in an incremental relationship, where $C\left(e_{2}\right)$ is a set of stages of $e_{2}$ (in the sense of Landman 2008), and $e_{2}$ is a BECOME event. The incremental relationship means that the parts of $e_{2}$ that are given by $C\left(e_{2}\right)$ can be mapped in a one-to-one way onto parts of $e_{1}$ that share the same temporal trace.

$$
\begin{aligned}
& \lambda x \lambda e \exists e_{1} \exists e_{2}\left[e=s\left(e_{1} \mathrm{t} e_{2}\right) \wedge \mathrm{P}_{\mathrm{ACTIVITY}}\left(e_{1}\right) \wedge \operatorname{th}\left(e_{1}\right)=x \wedge\right. \\
& \left.\operatorname{BECOME}-\mathrm{P}\left(e_{2}\right) \wedge \arg \left(e_{2}\right)=\operatorname{th}\left(e_{1}\right) \wedge \operatorname{INCR}\left(e_{1}, e_{2}, C\left(e_{2}\right)\right)\right]
\end{aligned}
$$

Essentially, (51) says that an event is an accomplishment if it is composed of an extended BECOME event whose stages can be lined up temporally with parts of an activity event. With this in mind, the core proposal for N-ZA-N is clear. It places requirements on the stages of the BECOME event, namely those events in $C\left(e_{2}\right)$. They must each satisfy the measure given by N-ZA-N. Thus, a sentence like (52) is interpreted like (53), where the last four lines give the contribution of N-ZA-N. ${ }^{8}$

Braginsky \& Rothstein 2008: ex. 46b

Ivan el cornfleks ložka za ložka.

Ivan ate cornflakes spoon by spoon

'Ivan ate cornflakes spoonful by spoonful.'

$$
\begin{aligned}
& \text { Braginsky \& Rothstein 2008: ex. } 49 \\
& \exists e, e_{1}, e_{2}\left[e=e^{s}\left(e_{1} \mathrm{t} e_{2}\right) \wedge \operatorname{EAT}\left(e_{1}\right) \wedge \operatorname{ag}\left(e_{1}\right)=\operatorname{JOHN} \wedge\right. \\
& \mathbf{t h}\left(e_{1}\right)=\operatorname{THE} . \operatorname{CORNFLAKES}(x) \wedge \operatorname{BECOME} \_ \text {EATEN }\left(e_{2}\right) \wedge \\
& \arg \left(e_{2}\right)=\operatorname{th}\left(e_{1}\right) \wedge \operatorname{INCR}\left(e_{1}, e_{2}, C\left(e_{2}\right)\right) \wedge \\
& \forall e^{\prime} \in C\left(e_{2}\right): e^{\prime} \in \operatorname{EAT}_{\mathrm{ACTIVITY}} \wedge \\
& \operatorname{MEAS}\left(e^{\prime}\right) \in \mathbf{R}_{\mathrm{SPOONFUL}} \wedge \\
& \operatorname{MEAS}\left(e_{2}\right)=\langle n, \operatorname{SPOONFUL}\rangle \rightarrow \\
& \left.\left.\forall n^{\prime}<n: \exists e^{\prime \prime} \in C\left(e_{2}\right): \operatorname{MEAS}\left(e^{\prime \prime}\right)=\left\langle n^{\prime}, \operatorname{SPOONFUL}\right\rangle\right)\right]
\end{aligned}
$$

In particular, the last four lines of (53) place conditions on the stages of the BECOME event $e_{2}$. First, each of the stages has to be an eating event. Second, each of those eating events must be measurable in terms of spoonfuls. Finally, for any eating event in $C\left(e_{2}\right)$ that is of spoonful measure $n$, there is a stage in $C\left(e_{2}\right)$ that is of spoonful measure $n-1$. This ensures that the BECOME event takes place in terms of single-spoonful increments.

While I am unable to address the Russian data head on (because Braginsky \& Rothstein 2008 does not discuss generalizations like those in section 2), there are good reasons to reject this analysis for English N-BY-N, even though it can

8 It is not clear why Braginsky \& Rothstein 2008 translates the object of (52) with a bare plural and (53) with the definite article. 
Quantizing scalar change

straightforwardly account for the data in section 2 . First, N-BY-N freely modifies VPs that are transparently not accomplishments. We can see this because N-BY-N and for-adverbials are not in complementary distribution.

(54) a. John ate cornflakes spoonful by spoonful for an hour.

b. The crack widened inch by inch for three hours.

c. The sailors lowered the leadline foot by foot for an hour, but it never struck bottom.

If N-BY-N must modify the stages of an extended BECOME event, that is, of an accomplishment, then the examples in (54) should be ungrammatical.

The second problem, which is related, is that N-BY-N need not modify a VP that denotes a BECOME event. Under its normal definition (Dowty 1979), $e$ is a BECOME $\phi$ event just in case $\neg \phi$ holds at the start of $e$ and $\phi$ holds at the end of $e$. As Kennedy \& Levin (2008) note, deadjectival verbs of scalar change cannot be analyzed via BECOME because open and lower-closed scale adjectives do not license the correct entailment.

a. The crack widened $\nRightarrow$ The crack is wide.

b. The soup cooled $\nRightarrow$ The soup is cool.

The analysis in (53) clearly predicts that N-BY-N can only modify BECOME events. This means that it should not be able to modify those VPs in (55), but the prediction is not borne out.

(56) a. The crack widened inch by inch (but it never got wide).

b. The soup cooled degree by degree (but it never got cool).

What both of these examples show is that it is wrong to tie the licensing of N-BY-N to the aspectual properties of the VP it modifies. Instead, N-BY-N cares only about whether it is modifying a VP that denotes events of scalar change.

While our analysis avoids the problems that one encounters when extending the analysis in Braginsky \& Rothstein 2008 to English, we have not critiqued the general strategy pursued in that work. ${ }^{9}$ Recall that their idea is that N-ZA-N is a flavor of postepenno 'gradually'. The fact that gradually is, in fact, grammatical with atelic interpretations of degree achievements suggests that this might be the case.

(57) a. The crack widened gradually for an hour (but it never got wide).

b. The soup cooled gradually for thirty minutes (but it never got cool).

9 I need to thank four anonymous SALT reviewers and Louise McNally for pressing me on this point. 
The problem with this route is that gradually has a wider distribution than N-BY-N. Examples (58-59) show that it is grammatical with verbs of non-scalar change, and thus patterns with other similar modifiers, but not N-BY-N.

(58) a. They left the stage gradually.

b. * They left the stage dancer by dancer.

c. They left the stage one by one.

d. Dancer after dancer left the stage.

a. They arrived for morning practice gradually.

b. * They arrived for morning practice player by player.

c. They arrived for morning practice one by one.

d. Player after player arrived for morning practice.

While it would interesting to explore the connections between gradually and N-BY$\mathrm{N}$, facts like these argue against a unified analysis. In fact, the data in (58-59) accord with the idea developed in the previous two sections. While gradually can modify various kinds of extended changes, N-BY-N only modifies scalar changes.

\section{Conclusions}

The distribution of N-BY-N has been the empirical focus of this work. While previous accounts like Braginsky \& Rothstein 2008 have recognized that N-BY-N involves measurement, this is the first paper that explores in detail the systematic connection between N-BY-N and scalar change. We have shown that N-BY-N can licitly modify a VP just when Kennedy \& Levin 2008 and Levin \& Rappaport Hovav 2010 predict it should denote a scalar change. The fact that N-BY-N has the predicted distribution is a new piece of evidence that supports their analysis. In particular, IT verbs must be able to denote scalar changes because, if not, we would have no explanation for why N-BY-N also easily modifies COS and IDM verbs, but fails to modify VPs that clearly cannot denote scalar changes. A unified analysis therefore demands classifying IT verbs with these other verbs of scalar change. We have also seen that N-BY-N can only modify IT verbs when they have an overt internal argument. Thus, the analysis not only supports the proposal that IT verbs need a unified analysis with COS and IDM verbs, but also the proposal that IT verbs stand apart by inheriting their scales from the physical extent of their internal arguments (Kennedy 2012; Levin \& Rappaport Hovav 2010).

Finally, the analysis improves our understanding of the interpretation of N-BY$\mathrm{N}$ adverbials on their own terms. It was shown that the two previous non-scalar accounts of N-B Y-N in English, namely Beck \& von Stechow 2007; Brasoveanu \& 
Quantizing scalar change

Henderson 2009, both overgenerate and undergenerate. To avoid this, the analysis must treat N-BY-N as a modifier of scalar changes. We also showed that it will be difficult to directly port the analysis in Braginsky \& Rothstein 2008 to English. The problem is that N-BY-N is not sensitive to the aspectual properties of the VP it modifies, as Braginsky \& Rothstein 2008 would predict.

\section{References}

Beck, Sigrid \& Arnim von Stechow. 2007. Pluractional adverbials. Journal of Semantics (2). 1-40.

Braginsky, Pavel \& Susan Rothstein. 2008. Vendlerian classes and the Russian aspectual system. Journal of Slavic Linguistics 1(1). 3-55.

Brasoveanu, Adrian \& Robert Henderson. 2009. Varieties of distributivity: one by one vs. each. In Neil Ashton, Anca Chereches \& David Lutz (eds.), Proceedings of Semantics and Linguistic Theory (SALT) 19, Cornell: CLC Publications.

Dowty, David R. 1979. Word Meaning and Montague Grammar. Dordrecht: Reider.

Hay, Jen, Christopher Kennedy \& Beth Levin. 1999. Scale structure underlies telicity in 'degree achievements'. In Tanya Matthews \& Devon Strolovitch (eds.), Proceedings of Semantics and Linguistic Theory (SALT) 9, 127-144. Cornell: CLC Publications.

Kennedy, Chris. 2012. The composition of incremental change. In Violeta Demonte \& Louise McNally (eds.), Telicity, Change, State: A Cross-categorical View of Event Structure, 103-121. Oxford: Oxford University Press.

Kennedy, Christopher \& Beth Levin. 2008. Measure of change: The adjectival core of degree achievements. In Louise McNally \& Chris Kennedy (eds.), Adjectives and Adverbs: Syntax, Semantics and Discourse, 156-182. Oxford: Oxford University Press.

Krifka, Manfred. 1989. Nominal reference, temporal constitution and quantification in event semantics. In Renate Bartsch, Theo Vennemann \& Johan van Bentham (eds.), Semantics and Contextual Expression, 75-115. Cinnaminson, NJ: Foris Pubns USA.

Krifka, Manfred. 1992. Thematic relations as links between nominal reference and temporal constitution. In Ivan Sag \& Anna Szabolcsi (eds.), Lexical matters, 29-54. Center for the Study of Language and Information.

Landman, Fred. 2008. On the differences between the tense-perspective-aspect systems of English and Dutch. In Susan Deborah Rothstein (ed.), Theoretical and crosslinguistic approaches to the semantics of aspect, vol. 110, 107-167. John Benjamins Publishing.

Levin, Beth \& Malka Rappaport Hovav. 2010. Lexicalized scales and verbs of scalar change. 46th Annual Meeting of the Chicago Linguistics Society (CLS). 
Lønning, Jan Tore. 1987. Mass terms and quantification. Linguistics and Philosophy 10(1). 1-52.

Ramchand, Gillian C. 1997. Aspect and predication. Oxford: Clarendon Press.

Schwarzschild, Roger. 2006. The role of dimensions in the syntax of noun phrases. Syntax 9(1). 67-110.

Zwarts, Joost. 1997. Vectors as relative positions: A compositional semantics of modified PPs. Journal of Semantics 14(1). 57-86.

Robert Henderson

Linguistics

5057 Woodward

Suite 10303

Detroit, MI 48202

rhenderson@wayne.edu 